\title{
Retraction Note to: Non-Bernoulli-Compatibility Truss Model for RC Members Subjected to Combined Action of Flexure and Shear Part I: Its Derivation of Theoretical Concept
}

\author{
Woo Kim* and Je-Pyong Jeong**
}

Received April 29, 2008/Accepted March 16, 2010

The Editor-in-Chief of KSCE Journal of Civil Engineering has decided to retract this article [1] because it has previously been published by Kim et al. (2003) [2]. Investigation by the Editorial Board revealed the article [1] is a translation of the entire text from the previously published article [2] without a proper citation. The Editorial Board considers this article to be redundant.

Neither author has responded to any correspondence from the editor about this retraction.

\section{References}

[1] Kim, W. and Jeong, J.-P. (2011). "Non-bernoulli-compatibility truss model for RC members subjected to combined action of flexure and shear, Part I: its derivation of theoretical concept.” KSCE Journal of Civil Engineering, Vol. 15, No. 1, pp. 101-108, DOI: 10.1007/s12205-011-0662-6.

[2] Kim, W., Jeong, J.-P., and Kim, D.-J. (2003). "Non-bernoulli-compatibility truss model for RC members subjected to combined action of flexureand shear, Part I: Its derivation of theoretical concept." Journal of the Korean Society of Civil Engineers, Vol. 23, No. 6A, pp. 1247-1256 (in Korean)

\footnotetext{
*Member, Professor, Dept. of Civil Engineering, Chonnam National University, Gwangju 500-757, Korea (E-mail: wkim@chonnam.ac.kr)

**Member, Post Doctoral Research Associate, Dept. of Civil Engineering, Chonnam National University, Gwangju 500-757, Korea (Corresponding Author, E-mail : safecon@paran.com)
} 